\title{
Propagação in vitro de Erythrina velutina
}

\author{
In vitro propagation of Erythrina velutina
}

\section{Geisa Moreira da CostaI Cristina Ferreira Nepomuceno ${ }^{I I}$ José Raniere Ferreira de SantanaIII}

\section{RESUMO}

Erythrina velutina (mulungu) é uma planta nativa do semiárido brasileiro que pode ser propagada via cultura de tecidos, o que poderá contribuir com a rápida multiplicação dessa espécie, além da redução de possiveis impactos ambientais. O objetivo deste trabalho foi estabelecer um protocolo de micropropagação para o mulungu utilizando explantes de plântulas assépticas obtidas in vitro. Para a indução de brotos, foram utilizados como explantes hipocótilos segmentos nodais e nós cotiledonares inoculados em meio de cultura WPM acrescido de diferentes concentrações de BAP e ANA. O enraizamento dos brotos foi realizado em meio WPM suplementado com 0,0; 2,46; 4,92; e 9,88 $\mu M$ de AIB. A melhor resposta para a multiplicação foi obtida em meio suplementado com 17,76 $\mu \mathrm{M}$ de BAP, sendo utilizado segmento nodal ou nó cotiledonar como explante. Os brotos enraizaram em todas as condições testadas, inclusive no meio de cultura sem auxina.

Palavras-chave: Mulungu, cultura de tecidos, micropropagação, reguladores de crescimento vegetal.

\section{ABSTRACT}

Erythrina velutina (mulungu) is a native plant of the semi-arid region that can be propagated via tissue culture, which may contribute to the rapid multiplication of this species, reducing the possibility environmental impacts. The objective of this study was to establish a protocol for micropropagation of mulungu using aseptic explants seedlings grown in vitro. For the induction of shoots, , nodal segments and cotyledons were used as explants hypocontyl and were inoculated in a WPM culture medium supplemented with different concentrations of BAP and NAA. The rooting of shoots was achieved in a WPM medium supplemented with 0.0; 2.46; 4.92; 9.88 $\mu \mathrm{M} I B A$. The best answer to the multiplication was obtained in medium supplemented with $17.76 \mu \mathrm{M}$ BAP using nodal segment or cotyledonary node explants. The shoots rooted in all conditions tested, including the culture medium without auxin.

Key words: Mulungu, tissue culture, micropropagation, plant growth regulator

\section{INTRODUÇÃO}

Erythrina velutina Willd. (Fabaceae), popularmente conhecida como mulungu, é uma espécie arbórea ornamental nativa da Caatinga, do Nordeste brasileiro e do Vale do São Francisco, sendo empregada no paisagismo, na regeneração de áreas degradadas e na medicina popular (LORENZI \& MATOS, 2008). A propagação dessa espécie pode ser efetuada pela via assexuada (NEVES et al., 2006) ou sexuada, sendo utilizados métodos tradicionais para superação da dormência tegumentar das sementes (SILVA et al., 2007). Entretanto, o extrativismo das sementes para utilização em artesanato tem reduzido sensivelmente o surgimento de novas populações na natureza e, em função disso, é necessário estudar métodos alternativos para a propagação de espécies nativas, de forma a dar subsídio aos plantios comerciais e a áreas de extrativismo e preservação ambiental (GUEDES et al., 2009).

Nesse contexto, as técnicas de cultivo in vitro representam uma importante alternativa para a

'Programa de Pós-graduação em Biotecnologia, Universidade Estadual de Feira de Santana (UEFS), 44031-460, Feira de Santana, BA, Brasil. E-mail: geisa.mcosta@gmail.com. Autor para correspondência.

IIPrograma de Pós-graduação em Botânica, UEFS, Feira de Santana, BA, Brasil.

IIIDepartamento de Ciências Biológicas, UEFS, Feira de Santana, BA, Brasil. 
produção de mudas e conservação dessa espécie, com destaque para a micropropagação, que permite obter mudas com características genéticas idênticas às da planta-matriz a partir de genótipos selecionados. As mudas produzidas são livres de vírus, uniformes e obtidas em um curto espaço de tempo (VILLA et al., 2008). Além disso, a clonagem in vitro é particularmente útil para a preservação de espécies ameaçadas de extinção, propagação de espécies que possuem sementes recalcitrantes ou de ciclo de vida longo (RODRIGUES et al., 2009).

$\mathrm{O}$ estabelecimento in vitro de explantes corresponde à primeira etapa de um sistema de micropropagação, tendo início na seleção dos explantes mais adequados para a posterior multiplicação. $\mathrm{O}$ tipo de explante deve ser escolhido de acordo com a sua capacidade para se adequar às condições in vitro, sendo recomendados os que contenham maior proporção de tecido meristemático por apresentarem uma maior capacidade de expressar a totipotência (GRATTAPAGLIA\& MACHADO, 1998).

Além da escolha do explante, o uso de reguladores de crescimento, tais como auxinas e citocininas, isolados ou em combinação, tem sido empregado, visando a um rápido crescimento de células, acompanhado do desenvolvimento organizado de raízes e da parte aérea (DINIZ et al., 2006). Embora nem sempre sejam necessárias no meio de multiplicação, as auxinas são utilizadas com o intuito de estimular o crescimento da parte aérea por meio da expansão e do alongamento celular e induzir raízes adventícias. As citocininas são indispensáveis para a quebra da dominância apical e indução de proliferação de gemas axilares (GRATTAPAGLIA\& MACHADO, 1998; KIELSE et al., 2009).

Diante do exposto e em razão da falta de relatos sobre a propagação assexuada de mulungu, o objetivo deste trabalho foi estabelecer um protocolo de micropropagação de plantas de E. velutina utilizando explantes de plântulas germinadas de sementes in vitro.

\section{MATERIAL E MÉTODOS}

Estabelecimento in vitro e condições experimentais. Para a obtenção de plântulas assépticas, sementes de $\boldsymbol{E}$. velutina foram escarificadas (SILVA et al., 2007) com minirretífica (Western ${ }^{\circledR}$ R-40) no lado oposto ao arilo e depois lavadas em água corrente por 10 minutos. Em câmara de fluxo laminar, estas foram desinfestadas com imersão em álcool a $70 \%$ por um minuto, seguido de solução de hipoclorito de sódio $\mathrm{NaOCl}$ (água sanitária comercial - 2,5\% de cloro ativo), com duas gotas de detergente neutro por 15 minutos, e lavadas quatro vezes em água destilada estéril. Em seguida, as sementes foram embebidas em água destilada esterilizada e depois de $24 \mathrm{~h}$ foram inoculadas em tubos de ensaio, contendo meio de cultura WPM (LLOYD\& MCCOWN, 1980).

As culturas foram mantidas em sala de crescimento na temperatura de $25 \pm 3^{\circ} \mathrm{C}$, com fotoperíodo de 16 horas, com radiação fotossintética ativa de 45 $60 \mu \mathrm{mol} \mathrm{m} \mathrm{m}^{-2} \mathrm{~s}^{-1}$ fornecidos por lâmpadas fluorescentes. $\mathrm{O}$ meio de cultura básico utilizado para todos os experimentos foi o WPM, suplementado com $30 \mathrm{~g} \mathrm{~L}^{-1}$ de sacarose, $7 \mathrm{~g} \mathrm{~L}^{-1}$ de ágar (Himedia ${ }^{\circledR}$ ), e o $\mathrm{pH}$ foi ajustado para $5,7 \pm 0,1$, antes da autoclavagem, utilizando-se $\mathrm{NaOH}$ ou $\mathrm{HCl}$ 0,1N. O meio de cultura foi autoclavado, com temperatura de $127^{\circ} \mathrm{C}$ e pressão de $1,05 \mathrm{~kg} \mathrm{~cm}^{-2}$, durante 15 minutos.

Foram utilizados como fonte de explantes segmentos de hipocótilo, nó cotiledonar e segmento nodal obtidos de plântulas assépticas com 14 dias de idade. Os explantes foram inoculados em meio de cultura WPM suplementado com $30 \mathrm{~g} \mathrm{~L}^{-1}$ de sacarose, solidificado com $7 \mathrm{~g} \mathrm{~L}^{-1}$ de ágar e acrescido de diferentes concentrações de BAP - 6-benzilaminopurina $(0,0 ; 2,22$; $4,44 ; 6,66 ; 8,88 ; 17,76 \mu \mathrm{M})$ e ANA - ácido naftalenoacético $(0,0 ; 1,34 ; 2,68 ; 5,37 \mu \mathrm{M})$.

$\mathrm{O}$ delineamento utilizado foi o inteiramente casualizado, em fatorial 3x6x4 (tipos de explantes $\mathrm{x}$ concentrações de BAP x concentrações de ANA), com cinco repetições de cinco explantes por tratamento. Aos trinta dias após a inoculação, foram avaliados o número de brotos (NB), o número de folhas (NF), o comprimento da parte aérea $(\mathrm{CPA})(\mathrm{em} \mathrm{cm}$, utilizando uma régua graduada de $30 \mathrm{~cm}$ ) e a matéria fresca $(\mathrm{MF}) \mathrm{e}$ seca (MS) da parte aérea (mg). A secagem do material foi feita na estufa com ventilação forçada, à temperatura de $60^{\circ} \mathrm{C}$, por 72 horas.

Os brotos obtidos in vitro com $1-2 \mathrm{~cm}$ de comprimento foram individualizados e transferidos para diferentes meios de enraizamento contendo diferentes concentrações de AIB - ácido indolbutírico $(0,0 ; 2,46$; $4,92 ; 9,89 \mu \mathrm{M})$. Cada tratamento foi repetido 12 vezes, sendo cada repetição composta por um tubo de ensaio contendo um broto. Após trinta dias, foram avaliadas a porcentagem de enraizamento, o número médio de raízes e o comprimento da maior raiz $(\mathrm{cm})$, utilizando uma régua graduada de $30 \mathrm{~cm}$.

As mudas regeneradas foram retiradas do tubo de ensaio e lavadas com água destilada, para remoção do excesso de meio de cultura. Em seguida, foram transplantadas para sacos de polietileno contendo terra vegetal e areia lavada (1:1), sendo cobertas individualmente com garrafas pet de 1L. 
Durante esse período, a tampa da garrafa pet foi desenroscada no terceiro e retirada no oitavo dia, com a garrafa retirada no vigésimo primeiro dia. Durante as três primeiras semanas de aclimatização, foi realizado o controle da intensidade luminosa, em que as plantas foram mantidas sob sombrite $30 \%$. As plantas foram regadas diariamente com água durante esse período, pela manhã. Aos 21 e 51 dias após o transplante, avaliou-se a porcentagem de sobrevivência das mudas.

Os dados foram transformados em $(\mathrm{x}+1)^{0,5}$ para a normalização de sua distribuição e submetidos à análise de variância e regressão, utilizando-se $5 \%$ de significância, via software SISVAR (FERREIRA, 2000).

\section{RESULTADOS E DISCUSSÃO}

A análise de variância revelou significância estatística para a interação tripla BAPxANAxexplante, para todas variáveis analisadas. $\mathrm{O}$ nó cotiledonar apresentou a maior capacidade de regeneração, seguido do segmento nodal, enquanto o hipocótilo não apresentou capacidade organogênica. Pôde-se observar que houve formação de brotos em todos os tratamentos testados, mesmo na ausência de reguladores de crescimento, exceto para o hipocótilo. Entretanto, a adição de BAP e ANA ao meio de cultura proporcionou aumento do número de brotos formados por explante (Figura 1A).

Para o número de brotos, à medida que foi aumentada a concentração de BAP, houve aumento no número de brotos formados, e a melhor resposta foi encontrada quando foram utilizados $17,76 \mu \mathrm{M}$ de BAP. Nessa condição, foi induzida em média a formação de 2,68 brotos por explante, sendo utilizados os explantes nó cotiledonar e segmento nodal. Entretanto, para o último explante, foi necessária a adição de $1,34 \mu \mathrm{M}$ de ANA ao meio de cultura (Figura 1B). Esse resultado foi semelhante ao obtido por FRABETTI et al. (2009), que obtiveram 2,8 brotos por segmento nodal de Teucrium fruticans em meio de cultura MS suplementado com $6,6 \mu \mathrm{M}$ de BAP e $0,053 \mu \mathrm{M}$ de ANA.

A adição de reguladores de crescimento em meios de cultura e um balanço adequado entre eles são importantes para desencadear processos organogenéticos em diversas espécies, como evidenciado aqui para $\boldsymbol{E}$. velutina. BERRIOS et al. (1991), trabalhando com quatro espécies de Erythrina (E. berteroana, E. costaricensis, E. fusca e E. peoppigiana), verificaram que a regeneração de brotos a partir do nó cotiledonar ocorreu apenas em $\boldsymbol{E}$. berteroana e E. costaricensis, quando utilizaram 8,88 ou $17,76 \mu \mathrm{M}$ de BA independente da adição de AIB no meio de cultura e no meio de cultura $4,92 \mu \mathrm{M}$ de
$\mathrm{AIB}+35,52 \mu \mathrm{M}$ de BA, obtendo, entretanto, uma baixa taxa de multiplicação (cerca de um broto por explante).

Os resultados encontrados neste experimento corroboram aqueles observados em diversas espécies lenhosas, como Myracrodruon urundeuva (ANDRADE et al., 2000), Schizolobium amazonicum (CORDEIRO et al., 2004) e Cabralea canjerana (ROCHA et al., 2007), em que também foi verificada baixa taxa de multiplicação. Segundo esses autores, isso pode ser explicado, em parte, pelas características morfogenéticas da própria planta, de possuir caule ereto e uma pequena copa. No entanto, os resultados aqui obtidos são inferiores àqueles encontrados para as espécies Prosopis laevigata, Searsia dentata, Sesbania drummondii e Mucuna pruriens, em que foi observada taxa de multiplicação de 3,$37 ; 6,1 ; 7,75$ e 12,6 brotos por explante, respectivamente (CHEEPALA et al., 2004; FAISAL et al., 2006; GONZÁLEZ et al., 2007; PRAKASH \& STADEN, 2008), utilizando o nó cotiledonar ou o segmento nodal em meio de cultura MS suplementado com diferentes concentrações de benziladenina (BA).

Para o comprimento da parte aérea, o melhor resultado foi obtido quando foram utilizados $2,68 \mu \mathrm{M}$ de ANA na ausência de BAP. Essa condição promoveu crescimento médio de $4,83 \mathrm{~cm}$ nos brotos obtidos a partir do nó cotiledonar. Foi observado que o comprimento da parte aérea diminuiu significativamente dentro de cada concentração de ANA à medida que aumentou a concentração de BAP (Figura $1 \mathrm{C}$ ). Em relação ao segmento nodal, notou-se a mesma tendência; entretanto, os brotos foram menores em relação aos obtidos a partir do nó cotiledonar, e o maior comprimento $(2,99 \mathrm{~cm})$ foi observado no meio contendo $1,34 \mu \mathrm{M}$ de ANA(Figura 1D). Diversos autores afirmam que o aumento da concentração de citocininas no meio pode provocar a diminuição do comprimento dos brotos (ERIG etal., 2002; NICIOLI etal., 2008; PURKAYASTHA et al., 2008). A diminuição do comprimento das brotações a partir de determinadas concentrações de citocinina pode decorrer de um possível efeito fitotóxico desse hormônio (GRATTAPLAGIA \& MACHADO, 1998), podendo ainda estimular a ocorrência de hiperidricidade e formação de folhas anormais (NICIOLI et al., 2008). Destaca-se que essas últimas características não foram observadas em nosso experimento.

Para a variável número de folhas por planta, o modelo matemático mais representativo foi $o$ quadrático, e os melhores resultados (10,12 folhas por planta) foram alcançados quando foram utilizados $4,44 \mu \mathrm{M}$ de BAP e $1,34 \mu \mathrm{M}$ de ANA no meio de cultura WPM, utilizando o nó cotiledonar como explante. A 


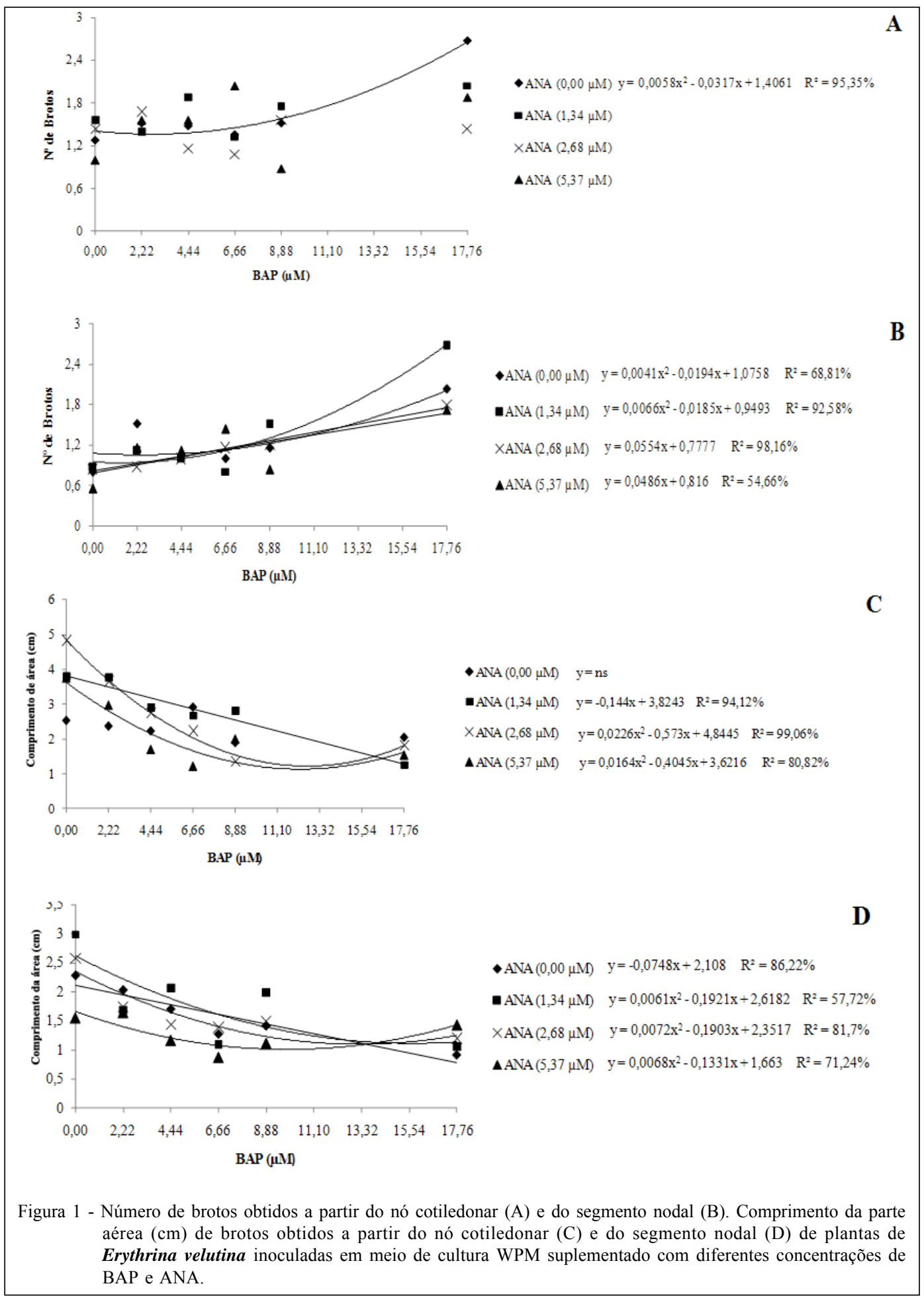

partir desse ponto, verificou-se uma diminuição no número de folhas, o que pode indicar fitotoxicidade do regulador de crescimento BAP (Figura 2A). Já quando se utilizou o segmento nodal como explante, foram observados um efeito linear crescente e um menor número de folhas por planta $(9,4)$ em comparação com o nó cotiledonar, no meio suplementado com $17,76 \mu \mathrm{M}$ de BAP e 1,34 $\mu \mathrm{M}$ de ANA (Figura 2B). O incremento no número de folhas na etapa de multiplicação é bastante favorável, pois na inserção entre o caule e a 


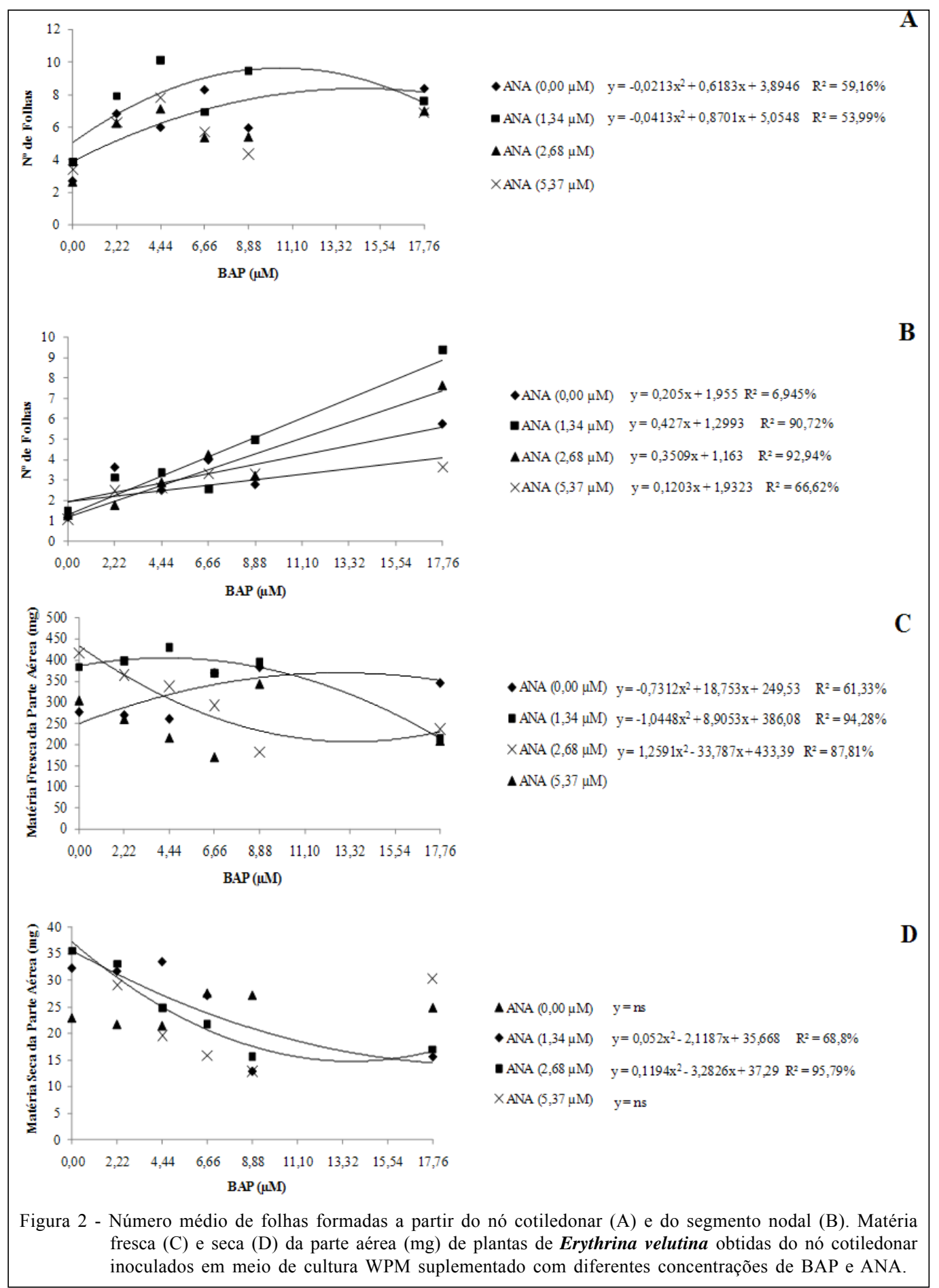

folha existe a produção de gema, a qual poderá dar origem a um novo broto e consequentemente aumentar a produção de novas mudas.

O maior valor para a variável matéria fresca da parte aérea $(429,12 \mathrm{mg})$ foi obtido quando se utilizou o nó cotiledonar como explante e meio de cultura suplementado com $4,44 \mu \mathrm{M}$ de BAP e $1,34 \mu \mathrm{M}$ de ANA.
A partir desse ponto, o regulador de crescimento BAP passou a inibir o desenvolvimento das brotações in vitro, apresentando um decréscimo na matéria fresca (Figura 2C). Resultado semelhante foi obtido na micropropagação de Rubus spp., em que a maior matéria fresca da parte aérea $(797,0 \mathrm{mg})$ foi alcançada até $8,88 \mu \mathrm{M}$ de BAP, e a partir desse ponto observou-se

Ciência Rural, v.40, n.5, mai, 2010. 
uma diminuição na matéria fresca (VILLA et al., 2006). Com a utilização do segmento nodal como explante, observou-se que não houve efeito significativo da interação BAP e ANA para essa variável.

Em relação à matéria seca da parte aérea, a interação BAPxANAxExplante foi significativa apenas para o explante nó cotiledonar. A análise de regressão apresentou efeito quadrático, atingindo o maior valor $(35,56 \mathrm{mg})$ no meio de cultura WPM suplementado com $2,68 \mu \mathrm{M}$ de ANA na ausência de BAP (Figura 2D). Observou-se, pelo modelo matemático, que houve diminuição do peso seco à medida que aumentou a concentração de BAP no meio. Esse resultado difere do obtido por BONILLA et al. (2007), que obtiveram um efeito linear positivo sobre o peso da matéria seca dos brotos de Rudgea viburnoides à medida que aumentou a concentração de BAP no meio de cultura.

Em relação ao enraizamento in vitro das brotações de $\boldsymbol{E}$. velutina, pôde-se observar que não houve diferença significativa para as variáveis número de raízes e comprimento da maior raiz na presença de diferentes concentrações de AIB. Ocorreu enraizamento dos brotos em todos os tratamentos, independentemente da concentração de AIB utilizada. No entanto, o maior percentual de brotos enraizados (75\%) ocorreu no meio de cultura WPM acrescido de $2,46 \mu \mathrm{M}$ de AIB. Resultados semelhantes ao encontrado no presente trabalho foram reportados por PARK et al. (2008), que observaram enraizamento de brotos de Salix pseudolasiogyne em meio de cultura WPM, na ausência de reguladores de crescimento. Em Arbus unedo L., os brotos também foram capazes de enraizar em todas as condições testadas, até mesmo na ausência de auxinas; entretanto, altas frequências de indução de raízes (entre 76,7 e 93,3\%) foram alcançadas com a adição de $25,0 \mu \mathrm{M}$ de AIB no meio de enraizamento por seis dias (GOMES \& CANHOTO, 2009). CARVALHO et al. (2005) também verificaram que o maior número de brotações enraizadas de Bixa orellana L. ocorreu no meio $1 / 2$ MS suplementado com 5,0 $\mu \mathrm{M}$ de AIB.

Quanto à aclimatização das plantas, verificou-se que, após 21 dias na casa-de-vegetação, do total de mudas transplantadas, aproximadamente $85 \%$ sobreviveram, sendo esse percentual mantido aos 51 dias.

\section{CONCLUSÃO}

A propagação clonal in vitro de Erythrina velutina é possível utilizando-se como explantes segmento nodal inoculado em meio de cultura WPM suplementado, com $17,76 \mu \mathrm{M}$ de BAP $+1,34 \mu \mathrm{M}$ de ANA, ou nó cotiledonar em meio de cultura WPM suplementado, com BAP $17,76 \mu \mathrm{M}$ de BAP ou $4,44 \mu \mathrm{M}$ de $\mathrm{BAP}+1,34 \mu \mathrm{M}$ de ANA. O enraizamento pode ser feito sem a adição de regulador de crescimento ao meio de cultura.

\section{AGRADECIMENTOS}

Os autores agradecem à Coordenação de Aperfeiçoamento de Pessoal de Nível Superior (CAPES), pela concessão de bolsa ao primeiro autor.

\section{REFERÊNCIAS}

ANDRADE, M.W. et al. Micropropagação da aroeira (Myracrodruon urundeuva Fr. All). Ciência e Agrotecnologia, Lavras, v.24, n.1, p.174-180, 2000.

BERRIOS, A. et al. Propagación clonal in vitro de diferentes especies de Poró. Turrialba, San José - Costa Rica, v.41, n.4 p.607-614, 1991 .

BONILLA, M.G.O. et al. Micropropagação de Rudgea viburnoides (CHAM.) BENTH., uma planta medicinal. Plant Cell Culture \& Micropropagation, Lavras, v.3, n.2, p.8995. 2007.

CARVALHO, J.R.F.P. et al. Regeneração in vitro de urucum (Bixa orellana L.) a partir de diferentes tipos de explantes. Revista Árvore, Viçosa, v.29, n.6, p.887-895, 2005. Disponível em: $<$ http://www.scielo.br/scielo.php?script=sci_arttext\&pid=S0100$67622005000600007 \& \operatorname{lng}=\mathrm{en} \& \mathrm{nrm}=\mathrm{iso} \& \mathrm{t} \operatorname{lng}=\mathrm{pt}>$. Acesso em: 28 de out. 2009. doi: 10.1590/S0100-67622005000600007.

CHEEPALA, S.B. et al. Rapid in vitro regeneration of Sesbania drummondii. Biologia Plantarum, Copenhagen, v.48, n.1, p.13-18. 2004.

CORDEIRO, I.M.C.C. et al. Efeito de BAP sobre a proliferação de brotos in vitro de Schizolobium amazonicum Huber ex Ducke (Paricá). Cerne, Lavras, v.10, n.1, p.118-124, 2004

DINIZ, J.D.N. et al. Multiplicação e enraizamento in vitro de guaco. Revista Ciência Agronômica, Fortaleza, v.37, n.1, p.59-64, 2006.

ERIG, A.C. et al. 6-benzilaminopurina e ácido indolbutírico na multiplicação in vitro da amoreira - preta (Rubus idaeus 1.), cv. Tupy. Ciência Rural, Santa Maria, v.32, n.5, p.765-770, 2002. Disponível em: $<$ http://www.scielo.br/scielo.php?script=sci_arttext\&pid=S0103$84782002000500005 \& \operatorname{lng}=\mathrm{pt} \& \mathrm{nrm}=\mathrm{iso} \& \mathrm{t} \operatorname{lng}=\mathrm{pt}>$. Acesso em: 28 de out. 2009. doi: 10.1590/S0103-84782002000500005.

FAISAL, M. et al. An efficient plant regeneration system for Mucuna pruriens L. (DC.) using cotyledonary node explants. In vitro Cellular \& Developmental Biology - Plant, Berlin, v.12, p.59-64, 2006.

FERREIRA, D.F. Análises estatísticas por meio do Sisvar para Windows versão 4.0. In: REUNIÃO ANUAL DA REGIÃO BRASILEIRA DA SOCIEDADE INTERNACIONAL DE BIOMETRIA, 45., 2000, São Carlos, SP. Anais... São Carlos: UFSCar, 2000. p.255-258.

FRABETTI, M. et al. Micropropagation of Teucrium fruticans L., an ornamental and medicinal plant. In Vitro Cellular \& 
Developmental Biology - Plant, Berlin, v.45, n.2, p.129134, 2009.

GOMES, F.; CANHOTO, Z.M. Micropropagation of strawberry tree (Arbus unedo L.) from adult plants. In Vitro Cellular \& Developmental Biology - Plant, Berlin, v.45, n.1, p.72-82, 2009.

GONZÁLEZ, L.B. et al. Clonal propagation of mesquite tree (Prosopis laevigata Humb. \& Bonpl. Ex Willd. M. C. Johnston) I. via cotyledonary nodes. In vitro Cellular \& Developmental Biology - Plant, Berlin, v.43, n.3, p.260-26, 2007.

GRATTAPAGLIA, D.; MACHADO, M.A. Micropropagação. In: TORRES, A.C. et al. Cultura de tecidos e transformação genética de plantas. Brasília: CBAB-EMBRAPA, 1998. p. 183-260.

GUEDES, R.S. et al. Resposta fisiológica de sementes de Erythrina velutina Willd. ao envelhecimento acelerado. Semina: Ciências Agrárias, Londrina, v.30, n.2, p.323$330,2009$.

KIELSE, P. et al. Regeneração in vitro de Parapiptadenia rigida. Ciência Rural, Santa Maria, v.39, n.4, p.1098-1104, 2009. Disponível em: <http://www.scielo.br/scielo.php?pid=S0103$84782009000400020 \&$ script $=$ sci_arttext\&tlng=e $>$. Acesso em: 28 de out. 2009 . doi: $10.1590 / \mathrm{S} 0103-84782009005000046$.

LLOYD, G.; McCOWN, B. Use of microculture for production and improvement of Rhododendron spp. HortScience, Alexandria, v.15, p.415, 1980. (Abst. 321).

LORENZI, H.; MATOS, F.J.A. Plantas medicinais no Brasil: nativas e exóticas. 2.ed. Nova Odessa: Instituto Plantarum, 2008. 577p.

NEVES, T.S. et al. Enraizamento de corticeira-da-serra em função do tipo de estaca e variações sazonais. Pesquisa Agropecuária Brasileira, Brasília, v.41, n.12, p.1699-1705, 2006. Disponível em: $<$ http://www.scielo.br/scielo.php?script=sci arttext\&pid=S0100$204 X 2006001200003 \& \operatorname{lng}=\mathrm{en} \& \mathrm{nrm}=\mathrm{iso} \& \operatorname{lng}=\mathrm{pt}>$. Acesso em: 28 de out. 2009. doi: 10.1590/S0100-204X2006001200003.

NICIOLI, P.M. et al. Ajuste do processo de micropropagação de barbatimão. Ciência Rural, Santa Maria, v.38, n.3, p.685-
689. 2008. Disponível em: <http://www.scielo.br/ s cielo.php ? s cript $=$ s ci_art text \& pid = S $0103-$ $84782008000300014 \& \operatorname{lng}=\mathrm{pt} \& \mathrm{nrm}=\mathrm{iso} \& \mathrm{t} \operatorname{lng}=\mathrm{pt}>$. Acesso em: 28 de out. 2009. doi: 10.1590/S0103-84782008000300014

PARK, S.Y. et al. Micropropagation of Salix pseudolasiogyne from nodal explant. Plant Cell, Tissue and Organ Culture, Netherlands, v.93, n.3, p.341-346, 2008.

PRAKASH, S.; STADEN, J.V. Micropropagation of Searsia dentata. In Vitro Cellular \& Developmental Biolology Plant, Berlin, v.44, n.4, p.338-341, 2008.

PURKAYASTHA, J. et al. Rapid in vitro multiplication and plant regeneration from nodal explants of Andrographis paniculata: a valuable medicinal plant. In Vitro Cellular \& Developmental Biology - Plan, Berlin, v.44, n.5, p.442447, 2008.

ROCHA, S.C. et al. Micropropagação de Cabralea canjerana. Revista Árvore, Viçosa, v.31, n.1, p.43-50, 2007. Disponível em: $<$ http://www.scielo.br/scielo.php?script $=$ sci_arttext\&pid $=\mathrm{S} 0100$ $67622007000100006 \& \operatorname{lng}=\mathrm{en} \& \mathrm{nrm}=\mathrm{iso} \& \mathrm{t} \operatorname{lng}=\mathrm{pt}>$. Acesso em 28 de out. 2009. doi: 10.1590/S0100-67622007000100006.

RODRIGUES, M. et al. Morfogênese in vitro de nim a partir de explantes cotiledonares. Revista Árvore, Viçosa, v.33, n.1, p.21-26, 2009. Disponível em: <http://www.scielo.br/ s c i e lo.php? s c ript=sci_art text \& pid=S $0100-$ $67622009000100003 \& \operatorname{lng}=\mathrm{en} \& \mathrm{nrm}=\mathrm{iso} \& \mathrm{t} \operatorname{lng}=\mathrm{pt}>$. Acesso em: 28 de out. 2009. doi: 10.1590/S0100-67622009000100003.

SILVA, K.B. et al. Quebra de dormência em sementes de Erythrina velutina Willd. Revista Brasileira de Biociências, Porto Alegre, v.5, supl.2, p.180-182, 2007.

VILLA, F. et al. Micropropagação da amoreira-preta (Rubus spp.) e efeito de substratos na aclimatização de plântulas. Acta Scientiarum, Maringá, v.28, n.1, p.47-53, 2006.

VILLA, F. et al. Crescimento in vitro de amoreira-preta: efeito de reguladores de crescimento e da cultivar. Ciência e Agrotecnologia, Lavras, v.32, n.6, p.1754-1759, 2008. 